\title{
O CAMPO DO CURRÍCULO NO BRASIL: CONSTRUÇÃO NO CONTEXTO DA ANPED
}

\author{
ANTONIO FLAVIO BARBOSA MOREIRA \\ Professor Titular da Faculdade de Educação da Universidade Federal do Rio de Janeiro \\ afmcju@infolink.com.br
}

\section{RESUMO}

O campo do currículo está se caracterizando, em diferentes países, por uma significativa diversificação de temas e de influências teóricas. Apoiando-se no conceito de campo de Bourdieu, o texto aborda o campo no Brasil, tal como vem sendo construído no Grupo de Trabalho - GT - de Currículo da ANPEd. Examina o funcionamento do grupo, procurando situá-lo no contexto mais amplo da associação e das políticas de pós-graduação. Focaliza, a seguir, os trabalhos apresentados nos encontros ocorridos no período de 1996 a 2000. Critica o grande número de textos selecionados, o que tem contribuído para a secundarização da discussão de problemas educacionais que carecem de atenção. Propõe perguntas e sugere estratégias que possam enriquecero processo de construção do conhecimento desenvolvido no GT. CURRÍCULO-CAMPO_GRUPODETRABALHO_CONSTRUÇÃODECONHECIMENTO

\section{ABSTRACTS}

THEFIELDOFCURR/CULUMINBRASIL: CURR/CULUMBUILDINGIN THECONTEXTOF ANPED. The field of curriculum has been characterized, in different countries, by a remarkable diversity of themes and theorethical infuences. Drawing on Bourdieu's conception of field, the article focuses on the field of curriculum in Brazil, as it has been constructed at the Curriculum Working Group - GT - of the National Association of Research and Graduate Studies in Education - ANPEd. It examines the dynamics of the meetings and analyses it taking into account both the main features of the Association and the recent educational policies for graduate studies in Brazil. It also discusses the papers presented in the meetings from 1996 to 2000. The author argues that the great number of papers has prevented the discussion of major educational problems that should be considered by the researchers. The article proposes questions and suggests strategies that could enrich the process of knowledge construction that has been developed by the Working Group.

CURRICULUM-FIELD-WORKING GROUP-KNOWLEDGECONSTRUCTION 
A insatisfação com os rumos do campo do currículo nos Estados Unidos, desde sua emergência nas primeiras décadas do século $X X$ até o início da década de 70 do mesmo século, levou numerosos pesquisadores a se engajarem no movimento que procurou promover sua reconceptualização. Unia-os a rejeição: a) ao caráter prescritivo e pretensamente apolítico dos estudos até então desenvolvidos; b) à ausência de uma perspectiva histórica, expressa no escasso diálogo entre as diversas gerações de investigadores; c) à excessiva preocupação em melhorar o trabalho desenvolvido nas escolas; d) à persistência de temas como objetivos escolares e planejamento; e e) à indefinição referente ao objeto de estudo do campo e às suas relações com outros campos. Herbert Kliebard (1975), um dos mais renomados participantes do grupo, chegou mesmo a sugerir que a tarefa para os cinqüenta anos subseqüentes deveria ser encontrar alternativas para o modo de refletir sobre currículo que dominou os primeiros cinqüenta anos do campo.

Nos vinte anos que se seguiram à eclosão do movimento de reconceptualização, foram intensos e frutíferos os debates sobre questões de currículo, em diferentes partes do mundo. Lições foram aprendidas, ainda que tenham restado dúvidas em relação aos rumos da teoria curricular, à promoção de práticas curriculares progressistas e ao desenvolvimento do diálogo entre os pesquisadores da universidade, os professores das escolas e os membros participantes de movimentos sociais (Silva, 1992).

Nos Estados Unidos, cuidadoso mapeamento do campo, realizado nos anos 90 do século $X X$, permitiu que se identificasse, nos textos sobre currículo, uma profusão de novos problemas, novas tendências e novas perspectivas. De duas tendências presentes na emergência do campo - uma voltada para os interesses da criança e outra para a formação do adulto supostamente necessário à sociedade chegou-se, em 1995, a um total de onze diferentes modalidades de textos - políticos, raciais, de gênero, fenomenológicos, pós-modernistas e pós-estruturalistas, biográficos e autobiográficos, estéticos, teológicos, centrados nas instituições escolares, históricos e internacionais. A preocupação com o desenvolvimento curricular praticamente desapareceu do cenário, passando a predominar o propósito de compreendero processo curricular (Pinar et al., 1995).

No Brasil, estudos recentes têm procurado traçar o panorama atual de nosso campo. Como nos Estados Unidos, identificou-se uma sensível diversificação das influências teóricas nas pesquisas entre nós (Macedo, Fundão, 1996). Discutiu-se a situação de crise da teoria curricular crítica, sugerindo-se, para sua superação, um empenho maior na investigação da prática curricular, bem como a promoção de freqüentes diálogos no campo do currículo (Moreira, 1998). Acentuou-se, ainda, 
com base em entrevistas com renomados pesquisadores da área, a necessidade de uma definição mais clara dos contornos do campo, de um maior diálogo entre a universidade e a escola, bem como de revisão dos métodos e dos conteúdos ensinados nos cursos de currículo no país (Moreira, 2000). Como nos Estados Unidos, o desenvolvimento curricular afastou-se das preocupações de nossos investigadores. Em síntese, nos estudos de currículo que temos desenvolvido evidenciam-se avanços, omissões e desafios a serem enfrentados.

O campo tem-se ampliado e diversificado cada vez mais. Produzem-se, com regularidade crescente, teses, dissertações, documentos oficiais, artigos e livros sobre currículo. Faz-se necessário, portanto, analisar mais profundamente esse conjunto de textos para que melhor se compreendam os caminhos seguidos, as tendências, os processos de produção, as conquistas, as lacunas, bem como as possíveis influências na determinação de políticas e de práticas. Este estudo insere-se nessa tarefa, visando, ainda que modestamente, favorecer sua consecução. Nele tomei como alvo de atenção o Grupo de Trabalho (GT) de Currículo da Associação Nacional de Pesquisa e Pós-Graduação em Educação - ANPEd - , instituição que promove, anualmente, o mais importante encontro de pesquisadores da área, limitando-me a examinar o funcionamento do GT e os trabalhos apresentados de 1996 a 2000.

No GT de Currículo reúnem-se docentes e discentes que se dedicam a investigar questões de currículo. Os mais produtivos autores do campo costumam comparecer às reuniões, fazendo com que o que se passa no GT corresponda, de fato, a uma caixa de ressonância do que se pesquisa sobre currículo no Brasil. Por conseguinte, um estudo sobre o GT pode certamente contribuir para o maior conhecimento do campo no Brasil. Talvez possa também, embora não seja seu propósito central, estimular reflexões sobre a forma como temos conduzido encontros, seminários e congressos na área da educação.

Meu texto desdobra-se, daqui para a frente, em cinco partes. Na primeira, esbocei um breve histórico do GT. Na segunda, procurei justificar o intenso emprego de perguntas no decorrer do estudo. Na terceira, apresentei o conceito de campo de Pierre Bourdieu, empregando-o para abordar a dinâmica do GT. Na quarta, focalizei os trabalhos selecionados para análise. Na quinta e última, ofereci sugestões para a superação de problemas que, a meu ver, ocorrem nos encontros do GT.

Não incluí, em minhas considerações, nem os trabalhos encomendados nem os textos elaborados por membros do GT para sessões especiais ou mesas-redondas. Ainda, não me sustentei em dados empíricos mais sistematicamente reunidos. 
Remeti-me ao funcionamento do GT utilizando uma perspectiva de dentro: desde 1989, ano seguinte a minha defesa de tese de doutorado na Universidade de Londres, tenho estado presente em todas as reuniões, o que já me levou a ser categorizado, inclusive em recente estudo (Cunha, 1997), como um membro histórico do grupo. Com a intenção de suscitar discussões, levantei questões relativas à dinâmica do GT.

Quanto aos trabalhos, focalizei-os com base em minha participação nas reuniões, em resultados de pesquisa que coordenei (Moreira, Macedo, 1997), na qual foram examinados os textos apresentados nas reuniões do GT durante a primeira metade da década de 1990, bem como em recente análise, que efetuei, dos que se apresentaram de 1996 a 2000. Tendo-me situado em relação aos temas e aos autores mais citados nas bibliografias, levantei questões sobre essa produção, buscando também provocar indagações e reflexões.

Antes porém das perguntas formuladas e das considerações teóricas que as embasam, passo ao histórico do GT.

\section{UM BREVE HISTÓRICO DO GT DE CURRÍCULO}

A decisão de organizar o Grupo de Trabalho de Currículo foi tomada na oitava Reunião Anual da ANPEd. O primeiro encontro de seus membros ocorreu em dezembro de 1985, no $1{ }^{\circ}$ Seminário Nacional de Currículo, promovido pelo Programa de Estudos Pós-Graduados em Supervisão e Currículo da Pontifícia Universidade Católica de São Paulo - PUC/SP. Algumas questões básicas orientaram as discussões no seminário e vieram a configurar, posteriormente, os eixos dos trabaIhos do GT que se formava: a reconceptualização do campo do currículo; o ensino de currículo na universidade brasileira; e a pesquisa em currículo no país. Procurouse também, durante o seminário, estabelecer os pontos a serem debatidos sobre o tema central da 9a Reunião - "Educação e Constituinte", ocorrida no Rio de Janeiro, em 1986.

Nessa oportunidade, o GT reuniu-se pela primeira vez, coordenado por Ana Maria Saul. Decidiu-se, então, desenvolver, em âmbito nacional, a pesquisa $\bigcirc$ Currículo do Ensino de Primeiro Grau, sob a responsabilidade de José Luiz Domingues, Iracema Lima Pires Ferreira, Ana Maria Saul e Nilda Alves.

$\mathrm{Na} 10^{a}$ Reunião, em 1987, em Salvador, procedeu-se à análise de entrevistas e de alguns dados coletados na pesquisa mencionada. Ao mesmo tempo, o grupo reservou espaço para a discussão de questões referentes à nova Lei de Diretrizes e Bases da Educação Nacional - LDBEN - e para a definição de compromis- 
sos a serem assumidos pelos membros do GT. Debateram-se, então, os mecanismos de mobilização necessários ao cumprimento desses compromissos. Ao final do encontro, José Luiz Domingues foi eleito o novo coordenador do GT.

Na I I Reunião, em 1988, em Porto Alegre, o grupo discutiu a pesquisa na área do currículo, bem como conteúdos e bibliografias da disciplina Currículos e Programas. Apresentaram-se também moções sobre a LDBEN. Certo consenso foi estabelecido ao final: o campo teórico do currículo carecia de melhor delimitação. Com base nessa constatação, propôs-se como tema do próximo encontro: a questão do currículo como matéria do pensamento pedagógico, visando-se à proposição de uma concepção de currículo mais significativa para a realidade brasileira.

Na I2a Reunião, em São Paulo, em 1989, os trabalhos do GT centraram-se em dois eixos: diretrizes e bases da educação brasileira - propostas específicas na área do currículo; e teoria do conhecimento e currículo. Duas decisões foram tomadas: elaborar um projeto de pós-doutoramento em currículo, no Brasil e no exterior; e sistematizar a história e a produção do GT. Iracema Lima Pires Ferreira foi eleita a nova coordenadora.

A I 3 a Reunião realizou-se, em 1990, em Belo Horizonte. Nela foram apresentados dez trabalhos de pesquisadores da área, além de um trabalho elaborado por Lucíola Santos, na época membro do GT de Didática. Voltou-se a discutir o projeto de pós-doutoramento e preparou-se a reunião subseqüente. Acordou-se que os trabalhos do ano seguinte deveriam focalizar: currículo e conhecimento; o fazer pedagógico do professor de Currículo; e pesquisas desenvolvidas na área. Cada um dos temas ficou a cargo de um ou dois integrantes do GT (Moreira, 1995).

A reunião de 1990 pode ser considerada, em razão do número de trabalhos e da dinâmica desenvolvida, um verdadeiro marco no funcionamento do GT, uma linha divisória. De 1991 em diante, os encontros passaram a privilegiar a apresentação de trabalhos. A discussão de políticas educacionais e temas emergentes e/ou de interesse dos pesquisadores precisou, quando ocorreu, de horários extraordinários. Os coordenadores subseqüentes foram Teresinha Fróes Burnham, Antonio Flavio Moreira, Nilda Alves, Alfredo Veiga-Neto, Alice Lopes e Sandra Corazza.

Vale ressaltar, ainda, que, mais recentemente, os trabalhos selecionados e apresentados nos encontros têm refletido a expansão de nosso sistema de pósgraduação e o modelo de avaliação implementado pela Coordenação de Aperfeiçoamento do Pessoal de Nível Superior - Capes. Ou seja, as transformações que se verificaram no GT precisam, a meu ver, ser relacionadas às mudanças que foram ocorrendo no panorama da pós-graduação em educação no país. Como uma das 
metas dos programas, em busca de maior pontuação nas avaliações, tem sido o aumento e a socialização da produção científica de mestrandos e doutorandos, os trabalhos apresentados no GT passaram a constituir-se, dominantemente, em versões condensadas de dissertações e teses defendidas, ou por defender. Com isso, lucram os programas, os orientadores e os orientandos. Estará de fato lucrando, com isso, o GT?

Com a ANPEd completando 25 anos de funcionamento em 2002, pode-se afirmar que os grupos de trabalho têm representado uma verdadeira força-motriz das reuniões anuais, propiciando significativo espaço de discussão, construção e reconstrução do conhecimento. Não se pode negar que os GTs têm estimulado e propiciado uma consistente e sistemática produção em diferentes áreas do campo educacional. Mas, cabe perguntar, será que as mudanças que se introduziram, principalmente nos anos de 1990, no funcionamento dos GTs, têm favorecido o desenvolvimento de saberes que se elaboram na tensão permanente entre a dimensão prático-pragmática e o domínio teórico-empírico do projeto educacional? (Brandão, 1998). Em outras palavras, em que medida as transformações ocorridas nos GTs têm de fato incrementado o avanço do conhecimento pedagógico e a realização de pesquisas pertinentes, voltadas para as candentes questões da educação brasileira?

\section{SOBRE PERGUNTAS E REFERENCIAIS TEÓRICOS}

Penso, como Fleuri (2000), que fazer perguntas pode ser um modo de orientar nossos olhares para vermos o que ainda não foi visto. Talvez seja mesmo um passo necessário à elaboração de uma linguagem para dizermos o que ainda não foi dito. Daí minha preocupação em formular perguntas, questões e hipóteses que nos estimulem a ver o que ainda não vimos e a melhor compreender o que ainda não compreendemos suficientemente.

Antes de começar a perguntar, recorro aos comentários de Beatriz Sarlo sobre a nostalgia. Minha intenção, ao citá-la em trecho a meu ver bastante expressivo, é antecipar-me às possíveis acusações de que estou sendo nostálgico ao lastimar o que se tem perdido com a consolidação do atual modelo de GT.

Há nostalgia? Melhor dizendo, há elementos no passado que não pareçam invariavelmente piores que os que se encontram no presente? Todo juízo que não afirme que o passado foi pior é nostálgico? Eu creio que a escola argentina foi mais eficaz para os setores populares do começo do século até a década de cinqüenta. Creio que o cinema italiano das décadas de cinqüenta e sessenta foi melhor que o atual. $\bigcirc$ 
mesmo acho do cinema francês dos anos sessenta. Sinto nostalgia por Visconti, por Truffaut ou pela escola número 14 do distrito escolar 15 em 1920? É nostálgico pensar que a escola em que as crianças aprendiam a ler e a escrever bem em quatro anos preparava os setores populares melhor que aquela que os deixa semi-alfabetizados quando abandonam a escola? É nostálgico quem pensa que a gente ganhava mais há dez anos atrás que agora?

Convenhamos que é absurdo afirmar que um juízo se torna nostálgico pelo simples fato de relacionar valorativamente presente e passado. Como não tenho superstição em relação ao passado, é possível que não me contamine com o otimismo experiencial do presente. (2001, p.225-226)

Pergunto, então: é nostálgico pensar que o GT de Currículo já promoveu reuniões mais produtivas que as atuais? É nostálgico considerar que o ambiente mais informal, menos burocratizado, do GT que inicialmente conheci, favorecia mais que o de hoje, tão regrado e controlado, o aprofundamento de temas que nos interessavam e sobre os quais julgávamos pertinente nos debruçar? É nostálgico julgar que a rapidez com que se apresentam e discutem inúmeros trabalhos acaba provocando menos interesse que as discussões travadas no "outro" GT? É nostálgico dizer que formávamos um grupo mais coeso e permanente que o de hoje, que se renova apressadamente à medida que um novo trabalho se sucede a outro?

Ainda com o suporte de Sarlo, sustento que ser nostálgico é querer introduzir no presente as condições passadas. Não é esta a minha intenção. Não a desejo, nem a vejo, mesmo, como possível. Todavia, insisto em que analisemos criteriosamente como temos conduzido nossos encontros e como, nas condições atuais, poderíamos abrir, como no passado, mais espaço para discussões que nos instiguem e para o exame cuidadoso de questões teóricas e práticas que devam ser enfrentadas. Ainda que os problemas que aponto no GT de Currículo possam também ser encontrados em outros GTs, precisamos buscar mecanismos próprios que nos permitam superá-los, ao menos parcialmente.

que estou tentando argumentar é que a rápida discussão de trabalhos advindos, dominantemente, de teses e dissertações defendidas em nossos programas de pós-graduação não tem sido adequada para recuperar, em nova forma, alguns elementos do GT passado que gostaria de ver preservados. Não se trata de desvalorizar as evidentes conquistas do presente, certamente facilitadas por aspectos do passado. Em outras palavras, tanto no passado como no presente encontram-se elementos a serem mantidos, elementos a serem renovados e transformados e elementos a serem rejeitados. Separar uns de outros constitui nossa tarefa, da qual não devemos nem podemos escapar. 
Conquistas e retrocessos precisam ser pensados no quadro mais amplo de mudanças sucedidas no panorama dos eventos educacionais e da pós-graduação no país. Na medida em que não mais se promovem as Conferências Brasileiras de Educação (a última realizou-se em 1991) e em que se vem reduzindo o espaço para a área da educação nas reuniões da Sociedade Brasileira para o Progresso da Ciência - SBPC - , é natural que haja aumentado consideravelmente o público nas reuniões da ANPEd. O encontro transformou-se, mesmo, em um megaevento, o que também se explica pela considerável elevação do número de programas de pós-graduação (temos hoje cerca de 55 programas recomendados pela Capes). Mais professores e mais estudantes, portanto, acorrem à reunião.

As mudanças sofridas no processo de avaliação dos programas, coordenado pela Capes, também contribuem para o aumento do público: como já comentei, cada vez mais se valoriza, na avaliação, a apresentação de trabalhos em eventos científicos, tanto por docentes como por discentes. Cada vez mais se abre espaço, no GT, para tais trabalhos. Nesse panorama, não constituem surpresa nem o aumento do número de grupos de trabalho (hoje igual a 20), nem a maior rigidez na forma da reunião, expressa tanto na introdução de um Comitê Científico e de consultores ad hoc para avaliar os trabalhos, como nas inúmeras regras para a organização dos encontros dos GTs, das mesas-redondas e das sessões encomendadas. A reunião, como um todo, burocratizou-se, na mesma proporção em que o GT, antes um estimulante espaço de discussões, se transformou em uma enfadonha "passarela" de trabalhos.

Proponho, então, mais perguntas. Como organizar nosso encontro de modo que favoreça discussões mais ricas e relevantes? Como poderíamos nos beneficiar mais dos trabalhos que vêm sendo apresentados? Como poderíamos reservar tempo suficiente para outros temas e problemas que muitos de nós desejariam discutir e aprofundar? Que aspectos do funcionamento do GT precisariam ser mudados e que aspectos precisariam ser preservados?

Cabe esclarecer que nada tenho, nem poderia ter, contra os trabalhos derivados dos relatórios das pesquisas feitas por estudantes da pós-graduação. Pelo contrário, como professor e orientador de pós-graduação, tenho tido o prazer de assistir a alguns de meus orientandos apresentarem e discutirem seus estudos no espaço deste GT. Das dissertações e das teses defendidas na pós-graduação têm derivado importantes contribuições para o pensamento pedagógico contemporâneo. Porém, julgo que essa produção discente, ainda que necessária, não é suficiente para garantir que se avance teórica e praticamente no campo do currículo. 
A fim de melhor desenvolver argumentos e apresentar minhas perguntas, inspiro-me no trabalho de Magda Soares (2000) sobre o campo da Didática. Soares recorreu ao conceito de campo de Bourdieu e o empregou não como uma teoria, mas como um método ou instrumento de análise. Desenvolveu sua reflexão como alguém que foi de dentro e hoje se encontra de fora dos Encontros Nacionais de Didática e de Prática de Ensino - Endipes. Apresentou hipóteses, em forma de perguntas, não afirmações, e esclareceu não se ter fundamentado em tratamento rigoroso de dados empíricos, mas em conhecimentos adquiridos em breve exame da programação dos nove encontros.

A trajetória de Soares é bastante similar à que pretendo seguir. Como já afirmei, também não me apóio em levantamento rigoroso dos temas e trabalhos discutidos nas reuniões do GT e também apresento perguntas que visam provocar estranhamento e inquietação. Ainda, também pretendo utilizar o conceito de campo de Bourdieu como um método ou instrumento de análise. Diferentemente, porém, situo-me como alguém que tem sido de dentro, como alguém que vem sistematicamente participando dos últimos 14 encontros. Por isso, embora também formule hipóteses, atrevo-me, em certos momentos, a sugerir respostas, causas, efeitos, ciente dos riscos que corro e da complexidade envolvida no processo. Como Soares, proponho-me a estimular reflexões que favoreçam a compreensão do que se passa no GT; diferentemente dela, atrevo-me a julgar e a avaliar procedimentos, práticas e resultados. Do mesmo modo, explicito também o conceito de campo com o qual trabalharei.

Antes, também conforme Soares, esclareço de que campo pretendo tratar. Vou focalizar o campo institucionalizado pelas reuniões do GT de Currículo, estruturado de modo a incluir as teorias, as práticas e as políticas de currículo, que correspondem às temáticas dominantemente tratadas nos trabalhos. Denomino-o, para fins da análise que efetuo, de campo do currículo, consciente dos problemas que podem resultar do emprego arbitrário e restrito do conceito de campo, tal como formulado por Bourdieu.

\section{SOBRE O CONCEITO DE CAMPO E PERGUNTAS QUE SUSCITA}

Pierre Bourdieu pode certamente ser considerado um dos maiores sociólogos da contemporaneidade. Seu pensamento marcou a Sociologia e suas obras são hoje referenciais, devido à fertilidade dos instrumentos conceituais que emprega para compreender as estratégias de reprodução da desigualdade e as lutas simbólicas que os agentes sociais travam, no plano cultural, por apropriação de bens e, 
conseqüentemente, por monopólio da competência e do poder. Dentre as categorias que utiliza, a noção de campo tem-se mostrado bastante fecunda, por relacionar-se às lutas que determinados grupos desenvolvem pela manutenção de vantagens e posições, ou seja, pela preservação de privilégios materiais e simbólicos. Nos diferentes campos - arte, religião, ciência, educação, esporte - evidenciam-se embates entre diferentes agentes, portadores de autoridade e legitimidade diferenciadas (Canesin, 2002). Para este estudo, foram particularmente úteis as análises que Bourdieu efetua sobre as disputas travadas no interior do campo científico. Nelas amparei-me para desenvolver minha argumentação.

Para Bourdieu (1983, 1997), campo é o universo no qual estão inseridos os agentes e as instituições que produzem, reproduzem ou difundem a arte, a literatura ou a ciência. É um mundo social como os outros, mas que obedece a leis sociais mais ou menos específicas, distintas das leis sociais a que está submetido o macrocosmo. Todo campo é um campo de forças e um campo de lutas para conservar ou transformar o campo de forças.

Referindo-se particularmente ao campo científico, Bourdieu (1983, 1997) argumenta que a estrutura das relações objetivas entre os diferentes agentes (que são as fontes do campo) comanda os pontos de vista, as intervenções científicas, os locais de publicação, os objetos a serem investigados. É essa estrutura que vai dizer o que pode e o que não pode ser feito. É, em síntese, a posição que os agentes ocupam nessa estrutura que define ou orienta seus posicionamentos.

Como se determina essa estrutura? Segundo Bourdieu, pela distribuição do capital científico, em um certo momento, entre os diferentes agentes engajados no campo. O capital científico é uma espécie particular de capital simbólico que consiste no reconhecimento concedido pelos pares, no seio do campo. Os maiores detentores de capital científico são certamente os pesquisadores dominantes. São eles que, em geral, indicam o conjunto de objetos importantes, ou seja, o conjunto de questões que devem importar para os pesquisadores e sobre as quais eles precisam se concentrar de modo a serem devidamente recompensados.

Algumas perguntas já podem, neste momento, ser formuladas. Que diferentes posições podem ser encontradas no campo do currículo? Que lutas se travam em seu interior? Quais são os pesquisadores dominantes? Quem tem de fato contribuído para determinar as questões, os métodos e os temas importantes, bem como para definir os arranjos e a burocracia do funcionamento do GT? Será que os trabalhos selecionados e apresentados refletem essas determinações?

Ainda segundo Bourdieu, no interior do campo está sempre em jogo o poder de impor uma definição da ciência, isto é, a delimitação do que pode ser consi- 
derado científico. A adoção da definição mais apropriada é necessária para que o pesquisador tenha seus talentos científicos reconhecidos e possa ocupar legitimamente a posição dominante na estrutura. Outras perguntas, então, mostram-se pertinentes: como, no seio do GT, tem-se determinado o que considerar como currículo e como forma apropriada de estudá-lo? Quem tem contribuído para essas determinações? Como elas têm afetado o caráter das investigações desenvolvidas?

Voltando a Bourdieu: à medida que estão em jogo na luta a própria definição dos critérios de julgamento e dos princípios de hierarquização, ninguém é bom juiz que não seja, ao mesmo tempo, juiz e parte interessada. Para Bourdieu, então, não pode ser visto como inocente o recurso a "juízes" para definir as hierarquias características de um campo determinado, seja a hierarquia dos agentes ou a das instituições. Assim, as análises "científicas" do estado da ciência não são inocentes; não são outra coisa senão a justificação, cientificamente mascarada, do estado particular da ciência ou das instituições científicas com a qual compactuam. Cabe, então, perguntar: como essa perspectiva se expressa nas avaliações dos consultores ad hoce do Comitê Científico? Que estado particular dos estudos de currículo e das instituições que os desenvolvem tem sido privilegiado nessas análises "científicas"?

Recorro, de novo, a Bourdieu: a estrutura da distribuição do capital científico está na base das transformações do campo científico e se manifesta por intermédio das estruturas de conservação ou de subversão da estrutura que ele mesmo produz. Em todo campo se situam, com forças mais ou menos desiguais segundo a estrutura da distribuição do capital no campo (grau de homogeneidade), os dominantes e os dominados, isto é, os "novatos". Na luta que os opõe, os dominantes e os "novatos" costumam recorrer a estratégias antagônicas, profundamente opostas em sua lógica e no seu princípio. Os interesses que os motivam e os meios que podem colocar em ação para satisfazê-los dependem estreitamente de sua posição no campo, isto é, de seu capital científico e do poder que tal capital lhes confere. Os dominantes consagram-se às estratégias de conservação, visando assegurar a perpetuação da ordem científica estabelecida com a qual compactuam. Segundo a posição que ocupam na estrutura do campo, os "novatos" podem orientar-se para as estratégias de sucessão, próprias para assegurar-lhes, ao término de uma carreira previsível, os lucros prometidos aos que realizam o ideal oficial da excelência científica, sem ultrapassar os limites autorizados; ou para as estratégias de subversão, investimentos mais custosos e arriscados, que só podem assegurar os lucros prometidos aos detentores do monopólio da legitimidade científica em troca de uma redefinição completa dos princípios de legitimação da dominação. 
Pergunto: em que medida, em nosso campo, distinguem-se de fato diferentes estratégias empregadas por dominantes e "novatos"? Quem emprega estratégias de conservação, quem emprega estratégias de sucessão e quem emprega estratégias de subversão? Como essas estratégias se evidenciam nas decisões referentes à organização do GT? Qual tem sido, nesse processo, o papel da diretoria da ANPEd e da coordenação do GT?

As estratégias que solidificaram o modelo implantando a partir de |99|, têm sido mais defendidas pelos "novatos" por razões que, a meu ver, sugerem mais mudanças na estrutura de relações do GT do que propriamente compromisso com o avanço do conhecimento científico. Ainda, penso que o tempo dedicado à apresentação de trabalhos visa propiciar o espaço necessário à maior divulgação de pesquisas desenvolvidas por mestrandos e doutorandos, conferindo aos autores e aos orientadores maior prestígio no GT e na comunidade acadêmica, assim como mais pontos na ficha de avaliação do programa na Capes. Mesmo que os pesquisadores dominantes também lucrem com a inclusão (muitas vezes provisória) de seus orientandos na "comunidade" do currículo, levanto a hipótese de que são os orientadores "novatos" os que mais se beneficiam (ou se beneficiarão) com a ampliação do tempo concedido aos trabalhos. Mas, cabe perguntar: são mesmo claras as distinções entre estratégias de conservação e estratégias de sucessão ou elas diferem apenas na ênfase maior ou menor dada à apresentação de trabalhos? Não estaria o GT carecendo de estratégias de subversão que de fato renovassem o debate no interior do campo e incrementassem a interlocução com outras áreas? Não estamos sendo um pouco passivos?

O grande problema, a meu ver, é que, nos trabalhos em pauta, costuma-se tratar de tudo (em alguns casos até mesmo não se discute currículo), característica que já marcou (e talvez, em certo grau, ainda marque) as teses e as dissertações defendidas em nossos programas. Em outras palavras, o que estou argumentando é que esse processo, por demais aberto, acaba por produzir um efeito de dispersão, já exaustivamente denunciado em análises de nossa pós-graduação (Warde, 1990; Cunha, 1991, 2002). Penso que o campo do currículo, ao qual me refiro, não constitui uma exceção. Julgo que, ao concedermos excessivo espaço para a apresentação de trabalhos, temos secundarizado tanto o aprofundamento de questões teóricas e metodológicas que demandam nossa atenção como os graves e persistentes problemas da educação brasileira, particularmente os que se incluem na esfera do currículo, que precisam ser mais bem entendidos e atacados. Quem lucra com isso? O GT? O campo do currículo? 


\section{TRABALHOS APRESENTADOS NO GT: 1996-2000}

Volto-me agora para a produção cientíica correspondente aos trabalhos apresentados no GT, de 1996 a 2000. Um exame das bibliografias permite que se constate a presença de autores associados ao currículo, tanto nacionais como estrangeiros. Os nomes mais freqüentemente citados, dentre os estrangeiros, são os de Michael Apple, Basil Bernstein, Deborah Britzman, Cleo Cherryholmes, Jean Claude Forquin, José Gimeno Sacristán, Henry Giroux, Ivor Goodson, Peter McLaren, António Nóvoa, Thomas Popkewitz, Jurjo Torres Santomé, Valerie Walkerdine. Dentre os nacionais: Nilda Alves, Sandra Corazza, Paulo Freire, Alice Lopes, Antonio Flavio Moreira, Lucíola Santos, Tomaz Tadeu da Silva, Alfredo VeigaNeto. São também freqüentes as citações a autores associados a outras áreas, pedagógicas ou não. Destaco: Theodor Adorno, Jean Baudrillard, Pierre Bourdieu, Michel Foucault, Gilles Deleuze, Michel de Certeau, Félix Guatarri, Stuart Hall, Jurgen Habermas, Jorge Larrosa, Edgar Morin, Nikolas Rose, Boaventura de Sousa Santos, Raymond Williams.

Pode-se observar que as bibliografias evidenciam, dominantemente, o recurso a especialistas em Currículo e a autores da Filosofia, da Sociologia, dos Estudos Culturais. A presença de autores pós-modernos e pós-estruturalistas é significativa. A presença de autores ligados à chamada ciência pós-moderna é rarefeita. São também escassas as menções a autores associados à Psicologia e à Antropologia e, mais raras ainda, as referências a autores relacionados à História, mesmo nos estudos de cunho histórico.

Um breve exame dos trabalhos evidencia preocupações com o cotidiano escolar, com a construção do conhecimento em redes, com distintos artefatos culturais, com propostas curriculares, com o multiculturalismo, com o poder de controle e de governo do currículo, bem como com a história do pensamento curricular e das disciplinas. Fortes críticas são explicitamente dirigidas à Didática, a Paulo Freire, à interdisciplinaridade. Não se encontram críticas abertas a outros autores, nacionais e estrangeiros, que se têm dedicado ao estudo de questões de currículo. Pouco se dialoga com as outras áreas pedagógicas, principalmente com a produção brasileira. Vale perguntar: lucra-se com esse escasso diálogo? Avança-se teórica e metodologicamente? Avança-se prática e pragmaticamente?

Como se pode observar, são variados os interesses dos pesquisadores que constroem o campo, assim como são diversificadas as fontes e influências teóricas. Não se observa uma concentração em determinados temas ou questões. Cabe 
indagar: lucra-se com essa dispersão? Avança-se teórica e metodologicamente? Avança-se prática e pragmaticamente?

Para continuar a perguntar, amparo-me em autores que têm em comum a preocupação com o processo de construção do conhecimento, tanto no campo da educação como fora dele. Seletivamente, escolho alguns de seus argumentos e a eles recorro para levantar questões. Emprego-os, como fiz com Bourdieu, mais como uma metodologia, com o propósito de incitar novas reflexões e novas trajetórias.

Começo com Wolf Lepenies ( 1983 ) e seu interesse no processo de formação de disciplinas, principalmente no século XIX. O autor propõe uma história das disciplinas que se desdobre com base no ponto de vista de que o ambiente cognitivo, histórico e institucional de uma disciplina deriva, essencialmente, dos ambientes configurados por outras disciplinas. Acrescenta, porém, que uma economia dos recursos requer que toda disciplina que pretende formular, sistematizar e institucionalizar um conjunto de idéias e práticas se esforce, também, por se distinguir de outras disciplinas. Somente assim poderá candidatar-se ao reconhecimento dos pares universitários e ao apoio de um público mais amplo.

Nessa perspectiva, a história das disciplinas corresponde a uma história dos associados e dos contemporâneos, na qual as séries de influências são menos importantes que a rede conformada pelas relações interdisciplinares. Em outras palavras, a história de uma disciplina seria a das relações com outras disciplinas, que ela toma como modelos, considera aliadas, tolera como vizinhos, rejeita como concorrentes ou menospreza como inferiores. Quero argumentar, contudo, que a apropriada ênfase nas relações entre as disciplinas não precisa acarretar a desconsideração das influências que se entrelaçam em uma disciplina. Por vezes, determinar essas influências pode favorecer uma melhor explicitação das relações que o especialista alemão intenta esclarecer.

Lepenies focaliza a Filosofia e procura construir sua história por meio do exame de suas relações tensas e complexas com outras disciplinas. Remete-se a dois processos: de um lado, a diferenciação de enfoques, de ramos e de especializações na Filosofia; de outro, a separação de novos domínios com relação à Filosofia. Exemplifica seus pontos de vista com as relações da Filosofia com a Psicologia, e da Filosofia com a Sociologia.

O campo do currículo, contudo, como campo de estudos e de práticas (Alves, 1999), não pode ser referido tão diretamente a uma diferenciação de enfoques e de especializações de uma dada disciplina e a uma posterior separação do novo conjunto em relação à disciplina. $O$ campo surgiu, na virada do século XIX para o 
$X X$, nos Estados Unidos da América, como já se destacou exaustivamente, de necessidades de ordem administrativa, que incluíram a organização e o controle das escolas e dos sistemas administrativos. Ao emergir, procurou apoio nos princípios da administração científica, ao mesmo tempo que tomou de empréstimo da Sociologia e da Psicologia comportamental seus pressupostos básicos e sua metodologia.

Os rumos posteriores do campo do currículo evidenciaram novos "empréstimos": nos anos de 1970, a Filosofia e a Teoria Social européia constituíram as principais fontes em que os estudiosos do currículo buscaram sustentação. A partir dos anos 90, os estudos culturais, o pós-modernismo, o pós-estruturalismo, os estudos de gênero, os estudos de raça, os estudos ambientais, dentre outros, passaram a fornecer a referência para a compreensão dos problemas e das questões envolvidas no campo do currículo em geral (Pinar et al., 1995). Certamente o exame das bibliografias, por mim empreendido, confirmou essa diversificação e indicou que o campo construído no GT de Currículo da ANPEd segue trajetória similar à de seus congêneres do Primeiro Mundo, parecendo mesmo caminhar, como sugere Alves (1999), mais por pontes e fusões do que pelos muros que delimitam os territórios disciplinares. Acresça-se, todavia, que especializações e separações evidenciam-se no interior do campo, observáveis, por exemplo, no desdobramento dos textos raciais e de gênero dos textos políticos.

A despeito das diferenças entre a Filosofia e o currículo, julgo que os pontos de vista de Lepenies são úteis para sugerir algumas perguntas. Que disciplinas podem ser vistas, no campo do currículo, como modelos, como aliadas, como vizinhos, como concorrentes, como superiores, como inferiores? Como entender as ênfases e as omissões? Como entender os empréstimos mais evidentes? Como se têm processado as pontes e as fusões? Que especializações e separações estariam ocorrendo no interior do campo? Em que medida tais processos indicam a construção de um campo centrado na formulação de teorias e na busca de soluções, parciais e aproximativas, para os problemas existentes e localizados na educação brasileira? Por que caminhos os conhecimentos produzidos no campo do currículo têm (ou não) entrado nas escolas? Que uso cotidiano tem sido feito de tais conhecimentos? Quem se tem beneficiado desse uso?

Volto a Lepenies, em sua apropriação por Mirian Warde (1998) para análise das questões teóricas e metodológicas enfrentadas pela História da Educação no Brasil. Examinando a presença dessa disciplina nos currículos da formação docente em nosso país, Warde destaca sua emergência como "irmã siamesa" da Filosofia da Educação, ressalta os esforços posteriores por construir uma História da Educação 
brasileira mais autônoma e por promover um diálogo com a Sociologia da Educação. Warde realça, por fim, a recente interlocução da História da Educação com a História, principalmente com a História Cultural. Sem dados disponíveis para afirmar que esse movimento de aproximação é de mão dupla, a autora levanta a hipótese de que o diálogo decorre mais da iniciativa dos que se situam na área da educação. Tais considerações estimularam-me outras perguntas. Nossos diálogos com as outras áreas do conhecimento constituem aproximações de mão dupla ou aproximações provocadas pelos especialistas em currículo? Por que se mostra débil o diálogo com autores de outros campos do conhecimento pedagógico, a despeito da ocorrência de sessões encomendadas e mesas-redondas que reúnem participantes de diferentes GTs? Será que nos move algum sentimento de superioridade em relação aos demais campos? Por que evitamos a crítica entre nós, pesquisadores do campo? Ainda: temos procurado comparar o trajeto de nosso campo com os trajetos em outros países? Com que resultados?

Recorro, agora, à Zaia Brandão (1998), cujo interesse pela identidade do campo da educação, como campo de produção de conhecimentos sistematizados, tem-se evidenciado em inúmeros estudos. Para ela, as investigações sobre fenômenos educacionais, em diferentes enfoques (sociológico, histórico, filosófico, psicológico) permitiram que se acumulasse um conjunto de conhecimentos que nem sempre se acomodou ou se articulou, sem disputa ou conflitos, nos espaços disciplinares já constituídos. A produção de conhecimentos sobre questões mais específicas dos processos educacionais - como ensinar, como selecionar e organizar conteúdos curriculares, como organizar e institucionalizar processos de socialização/ escolarização, como formar especialistas em educação - terminou por constituir uma base epistêmica, afastada dos tradicionais cânones disciplinares, legitimando um espaço próprio ao campo da educação. A seu ver, em uma perspectiva multi, inter ou transdisciplinar, os educadores vêm sistematizando conhecimentos em um processo de agregação ou articulação de diferentes tradições disciplinares.

Nessa perspectiva, cabe ao educador manter uma estreita vinculação com os campos científicos para melhor referenciar suas análises, opções e ações. No entanto, há que se evitar, em pesquisas pouco rigorosas, costuras ecléticas e incongruentes de perspectivas disciplinares distintas, sinais evidentes de um campo com escassa tradição disciplinar.

A socialização disciplinar facilita a incorporação de um ethos de trabalho que inclui: o exercício do pensamento sistemático, com base no conhecimento das formulações desenvolvidas pelos clássicos de uma disciplina; a capacidade de escolha dos concei- 
tos e referências teóricas mais adequadas à construção de um determinado objeto de pesquisa; e a capacidade de definir o recorte mais pertinente para problemas situados em um âmbito disciplinar. (Brandão, 1998, p. 103)

Por fim, devemos, ao nos aproximarmos dos diferentes campos disciplinares, estar atentos aos riscos de nos fascinarmos em demasia por novidades acadêmicas, novas roupagens e novas abordagens. Essa fascinação excessiva pode nos impedir o exercício constante de autocrítica e dificultar o necessário aperfeiçoamento da prática educacional que o conhecimento deve promover.

Antes das últimas perguntas que pretendo formular, volto-me para Franklin ( 1 974), um dos mais importantes estudiosos da emergência do campo do currículo, que chama a atenção para os riscos envolvidos quando conteúdos se transferem diretamente de um campo do conhecimento para outro. A seu ver, no campo em que os conteúdos são originalmente desenvolvidos existe um contexto auto-corretivo que responde por ajustes, modificações e redirecionamentos, permitindo que novas questões se levantem e novas respostas se elaborem. No campo em que as idéias são ancoradas, todavia, a ausência desse contexto, bem como a precariedade da interlocução entre os especialistas dos dois campos, pode ocasionar uma incipiente forma de recepção em que os elementos recebidos perdem seu dinamismo, seu vigor e, conseqüentemente, sua capacidade analítica. Franklin exemplifica seu ponto de vista argumentando que a categoria controle social, cunhada na sociologia no início do século $X X$ e integrada ao campo do currículo, sofre evidentes transformações em estudos sociológicos posteriores, preservando-se, contudo, inalterada nas reflexões e nas análises dos especialistas do novo campo pedagógico.

Proponho, então, mais perguntas. Como temos entendido rigor, ecletismo e incongruência em nossas pesquisas sobre currículo? Temos nos seduzido demais por novos paradigmas ou temos sabido exercer com acuidade a crítica e a recontextualização de idéias? Temos sabido ser ecléticos ou estamos inconsistentemente combinando o que não poderia ser sequer colocado lado a lado? Temos conseguido nos articular suficientemente com as chamadas disciplinas científicas de modo a dispensarmos o contexto autocorretivo, de que nos fala Franklin, ou ainda continuamos, como já fizemos em outros momentos, a empregar, apressada e limitadamente, parcelas ou formulações inicias de determinadas teorizações, ignorando perigosamente desdobramentos e transformações posteriores? Temos nos preocupado, ao construirmos os objetos de nossas pesquisas, em acompanhar, como sugere Brandão ( 1998), o que ocorre nas configurações concretas das práticas curriculares, das quais emergem as questões que nos são próprias? 


\section{CONSIDERAÇÕES FINAIS}

Conforme Soares (2000), vejo como saudáveis as lutas que se travam no campo do currículo em torno de posições, estratégias e definições. Se essas lutas não ocorressem, não teríamos um campo que se vem renovando e desenvolvendo. Por outro lado, a despeito das lutas, com certeza estamos todos interessados em preservar o campo, em deixá-lo existir, o que nos obriga, como acentua Bourdieu, a uma cumplicidade que se coloque além das lutas que nos venham opor. Ou seja, é indispensável que perdure a cumplicidade que nos une, apesar de eventuais antagonismos.

Com esse ponto de vista em mente, ofereço, além das perguntas formuladas ao longo do texto, algumas sugestões que, a meu ver, podem evitar fragmentações e desintegração do campo.

Em primeiro lugar, creio que se faz necessário um acordo, provisório e instável que seja, em relação ao que entendemos por um Grupo de Trabalho. É espaço privilegiado de apresentação de trabalhos ou é espaço de discussão e de aprofundamento das "questões que nos são próprias", de frutífera tensão entre ciência e política? Vejo como inadiável um maior equilíbrio entre o tempo reservado aos variados trabalhos produzidos em nossos programas de pós-graduação e as discussões de "nossas questões", que certamente não se esgotam nas abordadas nos trabalhos.

Em segundo lugar, penso que uma outra pesquisa sobre o campo mais amplo do currículo, no Brasil e em outros países, pode ser útil. Acredito que essa pesquisa, decidida no âmbito do GT, pode nos permitir melhor estabelecer, também em acordo instável e provisório, qual deve ser nosso objeto de estudo e quais as questões mais prementes sobre as quais devemos nos debruçar. Acrescento que toda essa discussão pode enriquecer as atividades de ensino que desenvolvemos nas nossas universidades. Recordo-Ihes que Kliebard, em 1975, já denunciava os riscos envolvidos na pouca clareza quanto ao objeto de estudo do campo do currículo, bem como de suas relações com outros campos.

Em terceiro lugar, sugiro que dialoguemos mais entre nós, estudiosos de currículo. $\bigcirc$ exame que fiz dos trabalhos apresentados levou-me a concluir que, em geral, caminhamos em vias expressas paralelas. Faltam intersecções, cruzamentos e choques. Os trabalhos derivados de teses e dissertações refletem muito a influência dos programas, dos orientadores e das linhas a que se filiam. Expressam, também, mais a aplicação de idéias e teorias que a formulação (ainda que inicial) de novas idéias e novas teorizações. Tendem, ainda, a não desenvolver críticas às po- 
sições antagônicas. No entanto, para que o novo de fato se crie, confrontos entre idéias, princípios e teorizações precisam ocorrer com mais freqüência. $\bigcirc$ conhecimento, como se sabe, caminha contra os conhecimentos anteriores, caminha com base nas críticas aos conhecimentos anteriores, buscando superar suas lacunas e equívocos. Para que isso aconteça, temos de nos criticar mais. Penso que somente assim avançaremos de fato e poderemos conferir maior autonomia ao campo do currículo que temos ajudado a construir. Mais uma vez recorro a Kliebard que, em 1975, alertava para a importância de adotarmos, em nossos estudos, uma postura histórica, o que requer um intenso diálogo entre os atuais pesquisadores do campo e deles com seus antecessores.

Por fim, retomo Beatriz Sarlo (200 I), pedindo-lhes, agora, que atentem para suas ponderações sobre as conferências. Para a autora, as universidades submeteram-se a uma espécie de pauta acadêmica segundo a qual os congressos, simpósios e painéis passaram a constituir parte relevante dos curricula vitae dos professores, obrigando-os a "condensações milagrosas em intervenções de quinze ou vinte minutos, com dez minutos absurdamente fugazes para uma discussão geral" (p. 1 84). A seu ver, essas intervenções orais somente em casos excepcionais conseguem provocar a pulsação necessária para torná-las um "acontecimento único". Usualmente, acabam por assimilar as características do show business. Vaidade e burocracia viram as marcas registradas. Mas, Sarlo acrescenta, em circunstâncias particularmente especiais, conferencista e público podem encontrar-se em um momento de necessidade verdadeira, romper a rotina, subverter as normas acadêmicas, burlar a "produção em série" e produzir "um acontecimento". Nesse sentido, situações menos formais e menos organizadas podem ser mais instigantes que os cenários das conferências e dos painéis. Não seria bom se nosso GT pudesse ser assim?

\section{REFERÊNCIAS BIBLIOGRÁFICAS}

ALVES, N. Tecer conhecimento em rede. In: ALVES, N.; GARCIA, R. L. (orgs.). O Sentido da escola. Rio de Janeiro: DP\&A, p. II I- 120, 1999.

BOURDIEU, P. O Campo científico. In: ORTIZ, R. (org.). Pierre Bourdieu. São Paulo: Ática, p. I22-155, 1983.

Les Usages sociaux de la science: pour une sociologie clinique du champ scientifique. Paris: INRA, 1997. 
BRANDÃO, Z. A Historiografia da educação na encruzilhada. In: SAVIANI, D.; LOMBARDI, J. C. SANFELICE, J. L. (orgs.). História e história da educação: o debate teórico-metodológico atual. Campinas: Autores Associados, 1998, p. 100-1 14.

CANESIN, M. T. A Fertilidade da produção sociológica de Bourdieu para as ciências sociais e a educação. In: ROSA, D. E. G.; SOUZA, V. C. (orgs.). Didática e práticas de ensino: interfaces com diferentes saberes e lugares formativos. Rio de Janeiro: DP\&A; Goiânia: Alternativa, p.85-101, 2002.

CUNHA, R. C. A Crise da legitimação da concepção crítica de currículo. Rio de Janeiro, 1997. Tese (Dout.) Faculdade de Educação da Universidade Federal do Rio de Janeiro.

A Inflexão insistente. In: SOUZA, D. B.; GAMA, Z. J. (orgs.). Pesquisador ou professor? O processo de reestruturação dos cursos de pós-graduação em Educação no Rio de Janeiro. Rio de Janeiro: Quartet, 2002, p.65-82.

Pós-graduação em educação: no ponto da inflexão? Cadernos de Pesquisa, n. 77, p.63-80, maio, 1991.

FLEURI, R. M. Entre o oficial e o alternativo em propostas curriculares: olhares, conexões e problematização a partir da educação popular. Caxambu, 2000. [Apres. na 23a Reunião Anual da ANPEd, na sessão especial "Propostas curriculares: entre o oficial e o alternativo"].

FRANKLIN, B. The Curriculum field and the problem of social control, 19/8-1938: a study in critical theory. Wisconsin, 1974, Tese (Dout.) Universidade de Wisconsin.

KLIEBARD, H. Persistent curriculum issues in historical perspective. In: PINAR, W. (ed.). Curriculum theorizing: the reconceptualists. Berkeley: McCutchan, 1975, p.39-50.

LEPENIES, W. Contribution à une histoire des rapports entre la Sociologie et la Philosophie. Actes de la Recherche em Sciences Sociales, v. 47-48, 1983, p.37-44.

MACEDO, E. F.; FUNDÃO, A. P. A Produção do GT de currículo da ANPEd nos anos 90. Caxambu, 1996. [Apres. na 19a Reunião Anual da ANPEd, no GT de Currículo]

MOREIRA, A. F. M. O Campo do currículo no Brasil: os anos noventa. In: CANDAU, V. M. (org.). Didática, currículo e saberes escolares. Rio de Janeiro: DP\&A, p.83-1 07, 2000.

A Crise da teoria curricular crítica. In: COSTA, M. V. (org.). O Currículo nos limiares do contemporâneo. Rio de Janeiro: DP\&A, 1998, p. I I-36.

. GT Currículo. In: ANPEd. Histórico dos grupos de trabalho. Belo Horizonte: ANPEd, p. I I- |4, 1995.

MOREIRA, A. F. B.; MACEDO, E. F. Transferência educacional e currículo. Rio de Janeiro: 1997. [Relatório de pesquisa apresentado ao CNPq] 
PINAR, W. F. et al. Understanding curriculum. New York: Peter Lang, 1995.

SARLO, B. Tiempo presente: notas sobre el cambio de una cultura. Buenos Aires: Siglo XXI, 2001 .

SILVA, T. T. O Que produz e o que reproduz em educação. Porto Alegre: Artes Médicas, 1992.

SOARES, M. 20 anos de Endipe: uma tentativa de compreensão do campo. In: CANDAU, Vera Maria (org.). Didática, currículo e saberes escolares. Rio de Janeiro: DP\&A, 2000. p. I 17 186.

WARDE, M. J. A História da educação nos marcos de uma história das disciplinas. In: SAVIANI, D., LOMBARDI, J. C.; SANFELICE, J. L. (orgs.). História e história da educação: o debate teórico-metodológico atual. Campinas: Autores Associados, p.88-99, 1998.

O Papel da pesquisa na pós-graduação em educação. Cadernos de Pesquisa, n. 73, p.67-75, maio 1990.

Recebido em: agosto 2002

Aprovado para publicação em: setembro 2002 